\title{
Multicultural Classroom Issues in the Nepalese Context
}

Dhanapati Subedi*

Abstract
Multicultural issue in the
present context is a global
issue of socialization. It has
not yet been materialized
into the education system in
Nepal. The education system
of a country should prepare
students to function in today's
diverse society. There are issues
emerging in the effectiveness
of the multicultural education
and the concerns how to
better shape the multicultural
classroom in Nepal. This
paper focuses on issues such as
curriculum design, classroom
management, and role of
the multicultural classroom
context. It also discusses the
context, and recommends
measures that can bring the
multicultural education into
thack.

\section{Introduction}

Macular and Page (2002) argue that a society has cooperation and conflict. Men cannot associate without cooperation, without working together in the pursuit of like or common interests. Many modes cooperation may for this preliminary survey be divided into two principle types as direct and indirect cooperation. In the similar way Ember et al (2002) say that culture refers to the total way of life of any society, not simply to those parts of this way which the society regards as higher or more desirable. It indicates that the culture is attached to life. Keeping this kind of view in mind the concept of multiculturalism was first recognized and systematically addressed in American educational settings basically following some concepts of the American educators, philosophers and leaders like Schwartz, James Banks, Martin Luther King, Sparks Varner, Banister, Maher and David Carper and so on. According to them, day by day, classrooms in the United States were influenced by multiculturalism onwards mid nineties in which Euro-centric academic system was unlikely to address those classrooms to meet the need of diverse identities assimilated in the classroom. There were several opinions for and against such situations regarding the curriculum that was left to develop. Anyway, educators have brought a conceptual change deviating from existing Euro- based academic values since the rate of immigrants are adding up every year by not less than one million in number. Besides, America, being purely a democratic country has granted lots of freedom from 1960s following civil rights movements lead by Afro-American and indigenous ethnic communities, principally led by Martin Luther King Junior.

\section{Key concepts of multicultural education}

Deviance is a common nature of individual in any society. Haralambus and Heald (2000) say that the deviance in a society

* Assistant Professor of ELT, School of Education, Kathmandu University 
$18 \mid$ Dhanapati Subedi

is a key feature of whole rather than individual. Such deviation is a threat to order and should be seen as dysfunctional for society. Next aspect common nature of the individual is acculturation that plays an important role in multicultural academic setting. Ember et al (2002) put their argument that acculturation refers to the change that occur when different cultural groups come into intensive contact as diffusion, the source of new cultural items is the other society. But more often than not, the term acculturation is used by anthropologists to describe situation in which one of the societies in contact is much more powerful than the other. Therefore, multiculturalism in education has been rephrased as multicultural education. There are various definitions of multicultural education coined by different educationists.

In the words of Boyer and Baptist (1996) as cited in Wagner's (2000) multicultural education is a process by which individuals and groups can learn to internalize the facts of cultural pluralism to bring about a society that recognizes cultural diversity. According to Woolfolk (2002) as cited in Wagner's (2000) multicultural education is one response to the increasing diversity of school population as well as to the growing demand for equality of all groups.

The goal of multicultural education is to prepare students to function in today's diverse society. Therefore, the teachers should teach children to respect the cultures and values of others; help children learn to function successfully in a multicultural society; promote the development of a positive self concept in those children who are most affected by racism, sexism, handicappism and so on and lastly, encourage children to view people of diverse cultures as unique parts of a whole community.

\section{Overview of the nature of multicultural classroom}

When one culture influences other cultures, the stratum of entire society will be multicultural and such stratum of society is unavoidable. Shrivastava (2005) says that social stratification is by no means a universal characteristic of human societies. There is no such thing as a society in which all the persons are perfectly equal. So, it is essential for a multicultural classroom to incorporate content from different cultures so that all cultures are considered valuable and wonderful. So, teaching strategies should include voices and experiences of all the students to prepare them for an intellectual society and common workplace. The teacher must create opportunities to utilize project based learning which encourages them to be cooperative to each other. In the case of homogeneous class it is especially important to emphasize multiculturalism because the only exposure of students may get to other cultures is through the activities, books and lessons the teachers provide them with. So, the classroom should be created with the lessons to raise awareness to address the issue on potentiality of harassment, violence, intimidation, bullying discriminations and other inappropriate form of conducts.

Next there must be adequate instructional instructions to facilitate dialogue based upon students. Then construction of knowledge to exemplify the democratic ideal of social justice, equality and human dignity of all students and to prepare them for work towards these ideals is the important thing for teachers. The best way to incorporate multiculturalism into classroom is to make a conscious effort to include books in curriculum and class library to feature multicultural character as much as possible. The curriculum should emphasize the integration of learning skills and multicultural educations which expose biases, stereotypes, inaccuracies and marginalization under repressed groups. The content must be relevant to facilitate to their everyday lives. At last, there must be integration of multicultural educational tools into classroom for pedagogical strategies to involve students in thinking critically, solving problems, questioning 
Multicultural Classroom Issues in the Nepalese Context $\mid 19$

and creating increased sensitivity to add awareness to different cultures.

\section{Experimented strategies in American classroom setting}

Assimilated classrooms alarmed a kind of fear that the students might not have a sense of nationality in addition to the possible benefit of overcoming challenges the teacher could get. Schwartz, a philosopher, seemed to have worried about the probable loss of American patriotism. He found a kind of imbalance in the existing American education system.

Banks (as cited in Wagner, 2000), another philosopher, came with certain ideas with fundamental steps of education system to challenge the problems seen in heterogeneous classrooms. He proposed that in the first stage, the students should be focused to admire American heroes, holidays, food and other discreet cultural elements which would help to instill American values to the students. In second stage, he proposed that the curriculum should focus on special units based on culture of particular ethnic group to teach them their own cultural values. In the third stage, he proposed that the Euro-centric curriculum should be replaced by various issues and events of various ethnic groups. In the same way, his fourth stage was that the students should be encouraged to decide on the concept related to the action and the issues they have studied which helps to honor nationality.

In this present context, the aim of education is not merely to enable individuals to read so as to render a capacity to obtain a profession for sustenance but it should also impart such values which would enable them to live better life in this global community interacting with people from varying socio-cultural settings. Students today are not merely the citizens of their country but are the global citizens living in the global village; and the education should equip these students with all the prerequisites of living as a global citizen such as the capacity to acculturate in different cultural settings, the capacity to tolerate and live up to the expectations of the other communities besides valuing one's own cultural norms. The teachers and curriculum designers of today, therefore, have not just a book but students of diverse cultural background to teach keeping a sheer concern about each of the student's cultural values and with a conviction that these diverse cultural aspects are nourished properly without any bits of biases.

Though there are handfuls of educators opposing the notion of multicultural education for the reasons of racial and cultural division among the students that may jeopardize the national unity, the consideration to multiculturalism, in today's democratic educational system and diverse society cannot be denied even to a negligible bit. Therefore, the notion of multicultural education that emerged in 1960s in the West bears a strong hold in the global educational scenario. At this juncture, teachers and curriculum designers should give forethoughts besides the other stake holders of educational system regarding the methods and materials to be devised for addressing the need of the diverse classrooms.

\section{Common perception on multiculturalism}

We believe, teachers must be knowledgeable and sensitive to multicultural issues. The teacher must have understanding of today's diverse student population and must avoid cultural generalization. In cases of such cultures in which teacher lacks knowledge, he must bring resource persons to help students understand this culture properly. Opportunities should be given to the students to share their own cultural experiences. In this way, a teacher needs to address the issues related to each of the students' culture so that the students feel his/her importance and freely contribute to classroom discussions. This will lead students join hands with the other students and help develop a classroom community. The students develop a feeling of 'our classroom'. The students must be taught how to live together interacting in meaningful ways without 
$20 \mid$ Dhanapati Subedi

dominating each other so that they learn how to work together to survive on this planet. The teacher must teach students the social skills necessary to interact with members of another culture.

Linton (as cited in Jha, 1999) says that a culture is the configuration of learned behaviour whose component elements are shared and transmitted by the members of a particular society. While pondering over the curriculum of multicultural education, the academicians came up with the opinion that curriculum should be designed to meet the cultural need of every group of students. Equal emphasis should be given to the cultural background of each of the students. For instance, while teaching about the famous personalities, the focus must be given to the heroes of the different cultures such as Jesus Christ of the Christian group, Prophet Mohammad of the Sheikh students or whatsoever might be the cultural composition of the students besides teaching about the heroes of the dominant cultural groups. Similarly, assessment of students should be done in such a way that no students are placed at the disadvantage level. The diverse learning strategies of the students, differences in language, preference to particular evaluation techniques should be considered while evaluating the progress of the students. Therefore, a single method of assessment should be discouraged. Assessment must involve observations, performance behaviors, selfreflections, portfolios, writing assignments, case study analysis, critical thinking, problem solving, creative productions, real and stimulated social and political actions, and acts of cross-cultural caring and sharing.

Those American experiments and practices forecasted such insight that, today's educators should keep a sheer concern that in today's world of democratic norms, consideration related to the issues of diverse culture, race, gender, ethnicity and so on must be focused so that all the students get equal opportunities to learn and grow in a congenial environment of mutual understanding, brotherhood and co-operation.

\section{Some burning multicultural issues in Nepal}

As Nepal has been divided into 4 races and 36 castes on the basis of profession which helped in establishing a kind of biased social hierarchy in which low caste people have still been victimized and marginalized from the mainstream of the center of national functioning. The issue of multicultural education is no more a foreign issue because we, the teachers in Nepal, too face the challenges of teaching students from multicultural background ranging from the Sherpa students of Mountain region born out of intractable Buddhists parents to the students from the plains of Terai heavily influenced by the Hindu religion. In this light, Nepalese teachers should teach about, Lord Shiva or Vishnu to emphasize the culture of Hindu students, Gautam Buddha to emphasize the culture the Buddhists students and so on.

Besides, the students of other religious background such as Christianity, Sheikh, Jainism and others too hold a good share in the roll registers of Nepalese classroom teachers. And on top of this, there is the prevalence of caste system with infinite branches of sub-castes within them bearing varying cultural values and practices. So, the issue of multiculturalism in education is relevant from the perspective of Nepal too besides its relevance in the other countries and communities. The curriculum should be inclusive of all these aspects but not just focusing on a particular personality of some dominant culture. And these aspects are to be taught together with the basic content of the curriculum. It should never be forgotten as Haralambos and Heald (2000) say with the functional emphasis on the importance of shared norms and values as the basic for social order; it could appear that deviance is a threat to order and should therefore seem as dysfunctional for society. 


\section{Multicultural Classroom Issues in the Nepalese Context 21}

Yet slowly and gradually the situation has been drastically worsen despite the slow pace development due to some slight updated academic curriculum and conduct and treatment of teachers towards so called marginally deprived students. Besides, the roles of upper-class people, human rights advocators and other national and international agencies have also contributed to some extent to end up such discriminating social hierarchy from the root. The social stratum of our country clearly indicates the country cannot survive without the slogan of national integration. Besides, it is essential to end up vertical relationship between the practices of center and margin issues by bringing change in behavior, thought and vision as they are most powerful weapons to eliminate the worry caused due to multiculturalism.

\section{Challenges and oOpportunities of multicultural classroom}

Giddens as cited in Slattery (2003) says the key to human behaviour is neither motivation nor self interest. It is rather man's capacity to know how to act in any situation and his / her capacity to adapt their behaviors should the situation require it. Man has the unique capacity for conscious or self conscious behaviour. He says man has hierarchy of thinking as discursive or reflective consciousness, practical consciousness and unconscious consciousness. The definition states that there are challenges, yet our focus is only concerned to classroom purpose.

There are some challenges as heterogeneous linguistic situation different levels of languages, different language contexts within language content realities, interaction in the classrooms, communication between the teachers and the students, students and students themselves, respecting the norms and values of each other's culture, adjustment and classroom setting, developing the students' participations , relationship between the teachers and students, pedagogical traditions in teaching, the forms of socialization and dynamic management of institution are some of the challenges seen in multicultural classroom.

In addition to challenges, it also promotes the rights of all people, enabling the students to understand issues and problems of diverse society, developing the intellectual level of teacher, making teacher a recourse people, updating teachers to learning how to deal with different cultures, ways of reasoning, the values beliefs, attitudes etc are some of the opportunities seen in multicultural classroom.

\section{Remedial procedures to addressing multicultural issues in Nepalese classroom}

Bottomore (1986) says almost all social changes are purposive, since the results from the purposive act of individual mean. But such acts may have unintended consequences, because the individual actions are not coordinated and may actually impede or distrust each other as, for example institution of conflict. After all it is teachers to address such situation in the classroom. So, the teacher should prepare their students feel for real multicultural world by drawing the world of students. The teacher should foster students' attitude of understanding, expectation, respect and to discuss differences and similarities in cultures with students openly but stressing the similarities helps to integrate heterogeneity into unity. Teachers in multicultural classroom must be open to the students and put forth the effort needed to get to know their students insight and outside of the class. Teachers need to pay attention to their verbal and non verbal language when he or she responds to students who speak differently. The teacher must evaluate the cultural diversities by building multicultural programs to show appreciation of differences avoiding stereotypes, acknowledged differences in children and discover the diversities within the classroom. Knopf (1998) says life, mind, society and culture are not outside the matter of energy, not outside space and time and free of them. They are in 
$22 \mid$ Dhanapati Subedi

and of nature with matter and energy. They are different organization of matter and energy, if one will, which the physicist and chemist cannot, in virtue of their physical and chemical methods, deal with fruitfully; and similarly all the way up to scale. Therefore the role of teacher should be concerned to all the dimensions.

Successful learning requires an inter cultural approach when students are responsible for listening and reading and experiencing to understand both the perspective of others and for understanding their own perspective and to know how they acquire them. They should try to understand the diverse culture influences impacting school, community, state, county, world etc. Students are to be involved in thinking critically, solving problems, questioning and creating increased sensitively to an awareness of different cultures. Students must be engaged in the teaching and learning process transcends the banking method and facilitated experiences in which students learn from each others experiences and perspectives. Some tips are listed as:

a) Ask about your students' interests and experiences so you can know them as individuals rather than merely the members of a group.

b) Encourage students to respond to each others' questions and comments, not just your own, to foster a sense of community.

c) Don't make assumptions about students based on what you perceive as their majority experiences and needs.

d) Provide guidelines for group discussions so as to create an environment where students will feel safe voicing their opinions.

e) Don't ignore or single out students and never ask a student to act as a spokesperson for his/her group.

f) Do not assume the identity or racial affiliation of a student based on his/her physical appearance.

g) When asking a student about his/her personal experience, stressing the student as an individual rather than a representative of a country will encourage the student without making him/her feel alien.

Besides the above points, I have from my own personal experience formulated the following remedial measures for teaching in a multicultural classroom. To make things clear, I have categorized them on the basis of classroom management, curriculum designing, and role of teachers and students in multicultural classroom.

\section{The classroom management for multicultural classroom}

Normally classroom invites conflict. Regmi (2003) says the conflict within the groups can benefit the group as long as it doesn't challenge the groups' purpose for the existence. Conflict can perform the functions of defining groups (external conflict) can perform the functions of defining group boundaries and of promoting cohesion within groups.

The nature teacher's address in general environment of the classroom will make a lot of difference in teaching learning process and the same is applicable in the case of multicultural classroom. From the perspective of my own experience, I have formulated the following requisites for a multicultural classroom:

a) Multicultural classroom should incorporate content from different cultures so that all cultures are considered valuable and wonderful.

b) Teaching strategies should include the voices and experiences of all students to prepare them for an intercultural society and workplace.

c) Create opportunities to utilize project based learning. 
d) In case of homogenous classroom, it is especially important to emphasize multiculturalism because the only exposure our students may get to other cultures is through the activities, books and lessons that we provide them with.

e) Create instructional interactions that facilitate dialogue based upon student constructed knowledge which exemplifies the democratic ideal of social justice, equality and human dignity of all students and prepares them to work towards these ideals.

\section{Curriculum designing for multicultural classroom}

Designing of curriculum too plays a vital role in addressing the issue of multicultural education; therefore, I have presented some of my views about multicultural curriculum. They are as follows:

a) The best way to incorporate multiculturalism into classroom is to make a conscious effort to include books in the curriculum and class library that feature multicultural characters as much as possible.

b) The curriculum should emphasize the integration of learning skills and multicultural education which expose biases, stereotypes, inaccuracies and marginalization of underrepresented groups.

c) Teaching and learning materials must be diverse and critically examined for biases.

d) Content and delivery should be made relevant for the students - facilitate experiences in which they connect it with their everyday lives.

e) Curriculum should be constantly assessed for completeness, accuracy and biases.

f) Multicultural education instructional tools should be integrated into the classroom pedagogical strategies to involve students in thinking critically, solving problems, questioning and creating increased sensitivity of different cultures.

\section{Role of Teachers in Multicultural Classroom}

To best facilitate multicultural education, the teachers' role is always crucial so as to solve the problem. The role of teachers is defined as under:

a) To prepare students for the real world and the real world is a multicultural one.

b) To draw on students' cultural experiences and knowledge

c) To foster attitudes of understanding, acceptance and respect.

d) To discuss the differences and similarities in cultures with students openly, but stress the similarities.

e) Teachers in multicultural classrooms should be open to their students and put forth the effort needed to know their students inside and outside of classroom.

f) Teachers need to pay attention to their verbal and non verbal language when he/she responds to students who speak differently

g) Evaluating cultural diversity, teachers should build multicultural programs, show appreciation of differences, avoid stereotypes, acknowledge differences in children and discover the diversity within the classroom.

\section{Role of Students in Multicultural Classroom}

The learners' attitudes and behaviors play a major role in determining how the issue of multicultural education is addressed; therefore, as per our frame of mind, I believe in the following role from the learners.

a) Successful learning requires an intercultural approach where students are responsible for listening, reading and experiencing to 
24

understand both the perspectives of others and for understanding their own perspectives and how they acquire them.

b) Students should understand the diverse cultural influences impacting school, community, state, country and the whole world.

c) Students are involved in thinking critically, solving problems, questioning and creating increased sensitivity towards awareness of different cultures.

d) Students must be engaged in the teaching and the learning process. Students should learn from each others' perspectives and experiences.

Besides the above remedial measures, the issue of multicultural education can be approached by devising appropriate teaching strategies such as peer tutoring, co-operative learning, mastery learning etc. Other instructional strategies can also be devised by the teachers as per the demand of the situation but while doing so; the teachers should ensure that the particular strategy fosters multiculturalism in the classroom. For instance, while teaching names of shapes, days of the week, greetings, months etc, and a teacher can include all languages represented in the classroom. Similarly, a teacher can also use resources other than textbooks that represent other cultures and ethnicities such as song, culture day activities, traditional dress, traditional food etc. And lastly but not the least, it is the attitudes of understanding and mutual co-operation amongst people representing different cultures that best addresses the issue of multiculturalism in education; therefore, all the people should harness themselves with the feeling of brotherhood and live up to the expectations of each other.

\section{Conclusion}

As Gautam (2007) says socialization is the process of learning it is mainly a matter of social cultural learning. In this process, an individual learns the social behaviour and cultural practices. In the same way, multicultural issue in the present context is a global issue of socialization as people are settling in every nook and corner of the world due to various reasons. Everywhere an individual seeks to save his identity and Nepal cannot be exception for that. Besides, Nepal has its own problem based on hierarchy of caste system. In addition to that there is a problem of religious, ethnical, political and geographical issues. Every community is trying to find a safe land. So, Nepalese multicultural curriculum must focus on those burning aspects by applying the procedures suggested above. If the nation hesitates to address all these areas, the country will be in a great crisis and invites irreparable loss. In other words, if the burning need of introducing multicultural curriculum is delayed and neglected, it will influence the nation fall into the vale of violence, protest, strike, kidnap, rape, robbery and mass brutality. It's been already late so the nation must immediately come with these issues to retain peace and harmony of the nation back.

\section{References:}

Haralambos, M. and Heald, R. M. (2000). Sociology: Themes and perspective. New Delhi: Cambridge University Press.

Shreevastava, A. R. N. (2005). Essentials of cultural anthropology: New Delhi: Prentice Hill.

Ember, C. E., Ember, M. and Peregrine P. N. (2002). Anthropology: New Delhi: Pearson Education.

Bottomore, T. B. (1986). Sociology: A guide to problem and literature. Bombay: Blackie and Sons.

Gautam, K. P. (2007). Introduction to anthropology and sociology. Kathmandu: Oxford International Publication.

Macular, R. M. and Page, C. H. (20002). Society 
Multicultural Classroom Issues in the Nepalese Context $\mid 25$

and introductory analysis. New Delhi: Replica Press Pvt. Ltd.

Regmi, R. R. (2003). The essentials of sociology. Kathmandu: Buddha Academic Publishers.

Slattery, M. (2003). Key ideas in sociology: Cheltenham: Nelson Thornes Ltd.

Jha, M. (1999). An introduction to anthropological thought. New Delhi: Vikash Publishing House.

Knopf, A. A. (1998). High points in anthropology: New York: Random House.

Wagner, D. (June 1, 2002) Teaching Strategies in Multicultural Education. Retrieved from http://csmstu01.csm.edu/st03/dwagner/ multicultural_education.htm. 